\title{
HIERARCHICAL MODELLING FOR RECYCLING-ORIENTED CLASSIFICATION OF SHREDDED SPENT FLAT MONITOR PRODUCTS BASED ON HYPERSPECTRAL IMAGING
}

\author{
Giuseppe Bonifazi ${ }^{1,2, \star}$, Riccardo Gasbarrone ${ }^{1}$, Roberta Palmieri ${ }^{1}$ and Silvia Serranti ${ }^{1,2}$ \\ ${ }^{1}$ Department of Chemical Engineering, Materials and Environment, Sapienza - University of Rome, via Eudossiana 18, 00184 Rome, Italy \\ ${ }^{2}$ Research Center for Biophotonics, Sapienza - University of Rome, Polo Pontino, Corso della Repubblica 79, 04100 Latina, Italy
}

Article Info:

Received:

21 November 2019

Revised:

31 July 2020

Accepted:

31 July 2020

Available online:

30 November 2020

Keywords:

Hyperspectral imaging

Hierachical modelling

WEEE

\begin{abstract}
The number of flat monitors from televisions, notebooks and tablets has increased dramatically in recent years, thus resulting in a corresponding rise in Waste from Electrical and Electronic Equipment (WEEE). This fact is linked to the production of new high-performance electronic devices. Taking into account a future volume growth trend of WEEE, the implementation of adequate recycling architectures embedding recognition/classification logics to handle the collected WEEE physical-chemical attributes, is thus necessary. These integrated hardware and software architectures should be efficient, reliable, low cost, and capable of performing detection/control actions to assess: i) WEEE composition and ii) physical-chemical attributes of the resulting recovered flow streams. This information is fundamental in setting up and implementing appropriate recycling actions. In this study, a hierarchical classification modelling approach, based on Near InfraRed (NIR) - Hyperspectral Imaging $(\mathrm{HSI})$, was carried out. More in detail, a 3-step hierarchical modelling procedure was designed, implemented and set up in order to recognize different materials present in a specific WEEE stream: End-of-Life (EoL) shredded monitors and flat screens. By adopting the proposed approach, different categories are correctly recognized. The results obtained showed how the proposed approach not only allows the set up of a "one shot" quality control system, but also contributes towards improving the sorting process.
\end{abstract}

\section{INTRODUCTION}

In recent decades, the volume of flat monitors deriving from televisions, notebooks and tablets present in Waste from Electrical and Electronic Equipment (WEEE) has increased dramatically (Zeng et al., 2018; Salhofer et al., 2011). Indeed, the continuous and rapid change in technologies rapidly renders devices obsolete, therefore proving easy to discard and replace with a newer version (Chancerel and Rotter, 2009; Oliveira et al., 2012; Palmieri et al., 2014). However, a significant amount of valuable materials is contained in WEEE, and metals and/or alloys, precious metals, and high-quality plastics can be profitably recovered. Copper, aluminum, lead and zinc are the main valuable non-ferrous metals contained in WEEE, although precious metals such as gold, platinum, palladium and silver may also be detected.

The implementation of a metal valorization action (i.e. recovery and recycling) at the end of an industrial process is a technological challenge, starting from a thorough char- acterization of this specific material stream (Bonifazi et al., 2018; Robinson 2009). One of the most interesting components of WEEE is represented by Printed Circuit Boards (i.e. $\mathrm{PCBs})$, rich in copper and potentially containing precious metals such as gold, silver and palladium (UNEP 2009). Plastics are utilized in electronic equipment manufacturing due to their excellent properties and low-cost, with polymers being lightweight, highly flexible and readily workable at low temperatures. As reported in Table 1, significant amounts of total generated WEEE are represented by polymers (Makenji et al., 2012; Ongondo et al., 2011). Flat monitors are viewed as a relatively "young" WEEE product due to their recent introduction onto the market. Different categories of materials may be recovered from this waste due to its heterogeneity. More in detail, liquid crystal displays (i.e. LCDs), focus of the present study, consist of several parts: top cover, lightbox unit (i.e. consisting of a metal frame, LCD glass panel, plastic frame, a number of plastic diffuser sheets, Perspex sheets, cold cathode fluorescent, reflective foil and lightbox support frame), PCB mounting 
frame, LCD control layer (i.e. PCBs, speakers, cables) and back cover (Ryan et al., 2011). Table 2 shows a typical LCD composition in terms of materials and weight (\%).

Polycarbonate (PC) or polymethyl methacrylate (PMMA) are found in End-of-Life (EoL) monitors and LCD screens (Tarantili et al., 2010; Suresh et al., 2017; Suresh et al., 2018). PMMA is used in monitors and screens for its optical clarity, high light transmission, toughness and high impact resistance, and both PCs or PMMAs are used in Light Guide Panel (i.e. LGP) manufacturing (Hwang and Ko, 2019). LGP is often present in EoL monitors and LCD screens (Lee et al., 2006; Suresh et al., 2018), as a part of backlight units (BLU). The identification of these plastic-based fragments is therefore crucial for recycling purposes, in order to obtain "waste-recovered" polymers for reuse (Suresh et al., 2017). PMMA and optical enhancement films are of pure optical quality and suitable for re-use and alternative applications (Veit and Bernardes, 2015). The recovery and reuse of flat monitor optical components for high-end applications may also contribute towards achieving economical sustainability for small and medium recycling plants (Ljungkvist et al., 2016).

The treatment of EoL monitors and LCD screens involves a series of complex activities: manual disassembly, removal of hazardous components (i.e. mercury-containing fluorescent lamps, CCFL from LCD panels) and mechanical recycling (i.e. size reduction and sorting stages). Typically, materials having a commercial value that can be recovered from flat monitors include metals (i.e. zinc-coated steel, aluminum and cable copper content), PCBs, PMMA light diffusers, optical enhancement films and recyclable plastics ABS, HIPS and polycarbonate (Veit and Bernardes, 2015). Indeed, heterogeneous materials such as metals, PCBs, electrical components and plastics were detected in the analyzed sample. These product ranges are of considerable interest for their residual economic value in a full circular economy logic. More in detail, a Near Infrared (NIR) - Hyperspectral Imaging (HSI) based approach was applied to characterize materials in the analysed sample, in order to define quality control/sorting logics in a recycling scenario.

Due to the potential risks associated with the incorrect treatment of WEEE and the considerable amount of "resources" contained in these wastes, it is essential to en-

TABLE 1: Typical materials contained in a WEEE product (Makenji et al., 2012)

\begin{tabular}{l|c}
\hline Material type & Weight (\%) \\
\hline Metals & 60 \\
\hline Plastics & 15 \\
\hline $\begin{array}{l}\text { Cathode ray tube (CRT) and liquid crystal display } \\
\text { (LCD) screens }\end{array}$ & 12 \\
\hline Metals/plastic mixture & 5 \\
\hline Pollutants & 3 \\
\hline Cables & 2 \\
\hline Printed circuit boards & 2 \\
\hline Others & 1 \\
\hline Total & 100 \\
\hline
\end{tabular}

sure the implementation of appropriate actions in a WEEE recycling process, both from an economic and environmental point of view. Generally, the chemical composition and physical properties of a material will define the recycling options available. Therefore, the importance of characterization is linked to the possibility of developing processing steps aimed at the recovery of secondary raw materials for use in a range of industrial applications. The present study was carried out in line with this perspective.

\section{MATERIALS AND METHODS}

\subsection{Samples}

The samples analyzed (Figure 1) consisted of EoL flat monitors and screens originating from a shredding line (i.e. hammer mill shredder) of a WEEE recycling plant, following semi-automatic disassembling aimed at removing the main electronic components. Sample collection was performed by a coning and quartering procedure, followed by manual sorting; each collected and analyzed sample weighed 215 g. The main components detected in the samples studies included Light Guide Panel (LGP) fragments, black plastics, metals, PCBs and electrical components and other materials (i.e. different polymers/plastics and cellulose-based particles). Weight percentages of the hand-sorted material categories are shown in Figure 1.

In order to build the hierarchical classification model, the sample was split into two sub-sets: i) a training set to calibrate the classification model and ii) a validation set to validate the model. The training set was composed of 228 particles (77\% in weight of the sample), subdivided according to material categories: "LGP fragments" (33 Wt\%), "Black plastics" (25 Wt\%), "Metals, PCBs and electrical components" (32 Wt\%) and "Other" (10 Wt\%), whilst the validation set was made up of 68 particles (approx. 23\% in weight of the total sample). Nine hyperspectral images were acquired: 7 images were used for training purposes, while 2 images were used to validate the hierarchical model (Figure 2).

\subsection{Hyperspectral imaging}

HSI utilizes an integrated hardware and software architecture to digitally capture and handle spectra (Hyvarinen

TABLE 2: Typical materials contained in an LCD (Ryan et al., 2011).

\begin{tabular}{l|c}
\hline Material type & Weight (\%) \\
\hline Ferrous & 45 \\
\hline Plastic & 21 \\
\hline PCBs & 10 \\
\hline Glass & 9 \\
\hline Non-Ferrous & 3 \\
\hline Speaker & 3 \\
\hline Hips & 2 \\
\hline Sheets & 2 \\
\hline Others & 6 \\
\hline Total & 100 \\
\hline
\end{tabular}




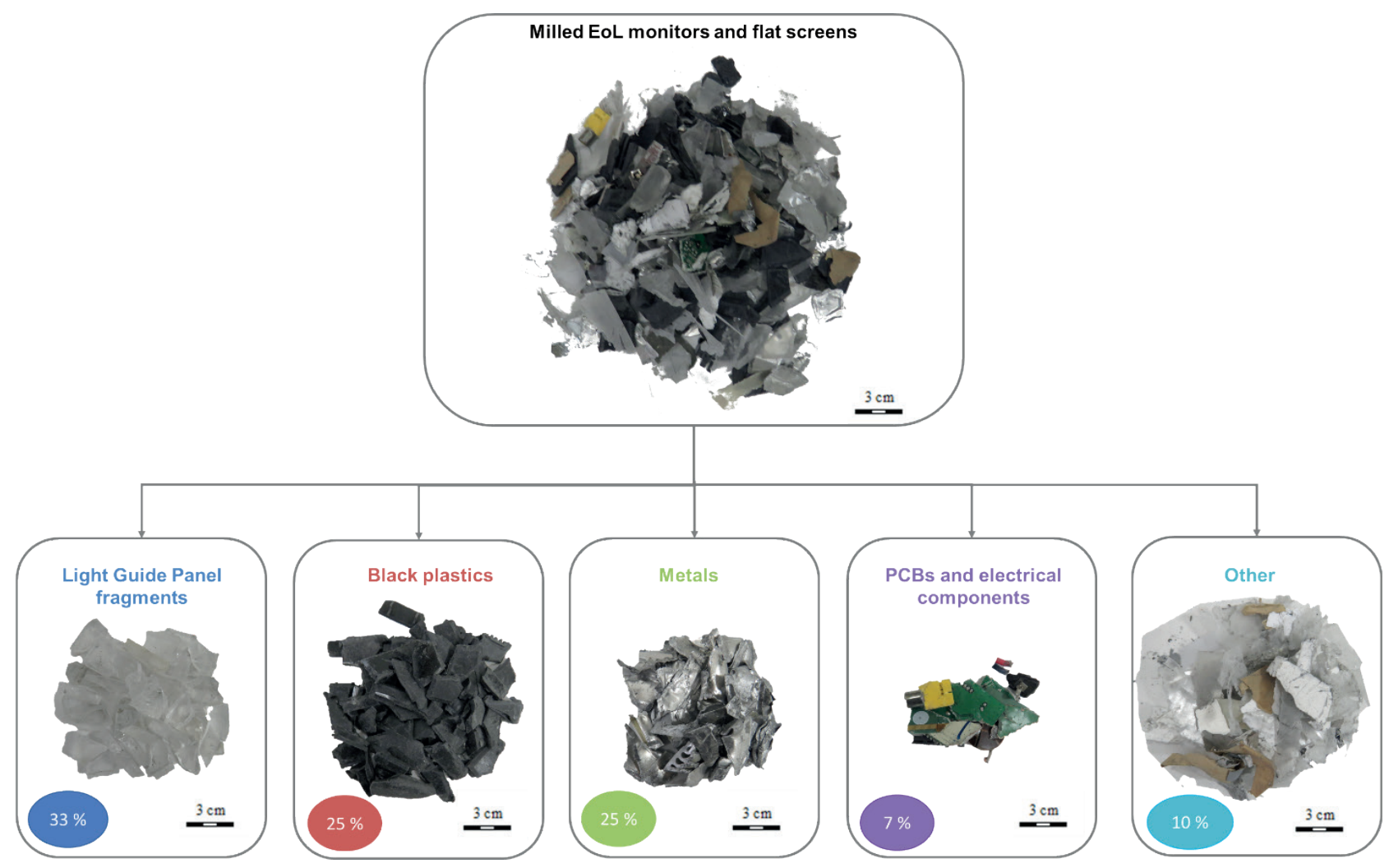

FIGURE 1: Diagram of the analyzed sample: product resulting from a milling line of a WEEE recycling plant and main material categories resulting from manual sorting. The composition (weight \%) of the different main material categories is reported.

et al., 1998; Geladi et al., 2007), allowing both spatial and spectral information to be collected concomitantly from the investigated material. This information is enclosed in a 3D dataset (i.e. the "hypercube"), in which two dimensions are spatial and the other provides spectral information. The HSI technology facilitates the study of several physical and chemical characteristics of a sample: different features can thus be analyzed according to the investigated wavelengths.
NIRS (Near InfraRed Spectroscopy) techniques are utilized to perform both qualitative and quantitative analysis in different fields: i.e. in the primary/secondary raw materials sector (Masoumi et al., 2012; Bonifazi et al. 2015), in cultural heritage (Agresti et al., 2013; Capobianco et al., 2015), in the agricultural and food industry (Teixeira dos Santos et al., 2013; Kumuravelu et al., 2015; Tsuchikawa et al. 2015; Serranti et al. 2018a; Serranti et al. 2018b), in the pharmaceutical and chemical industry
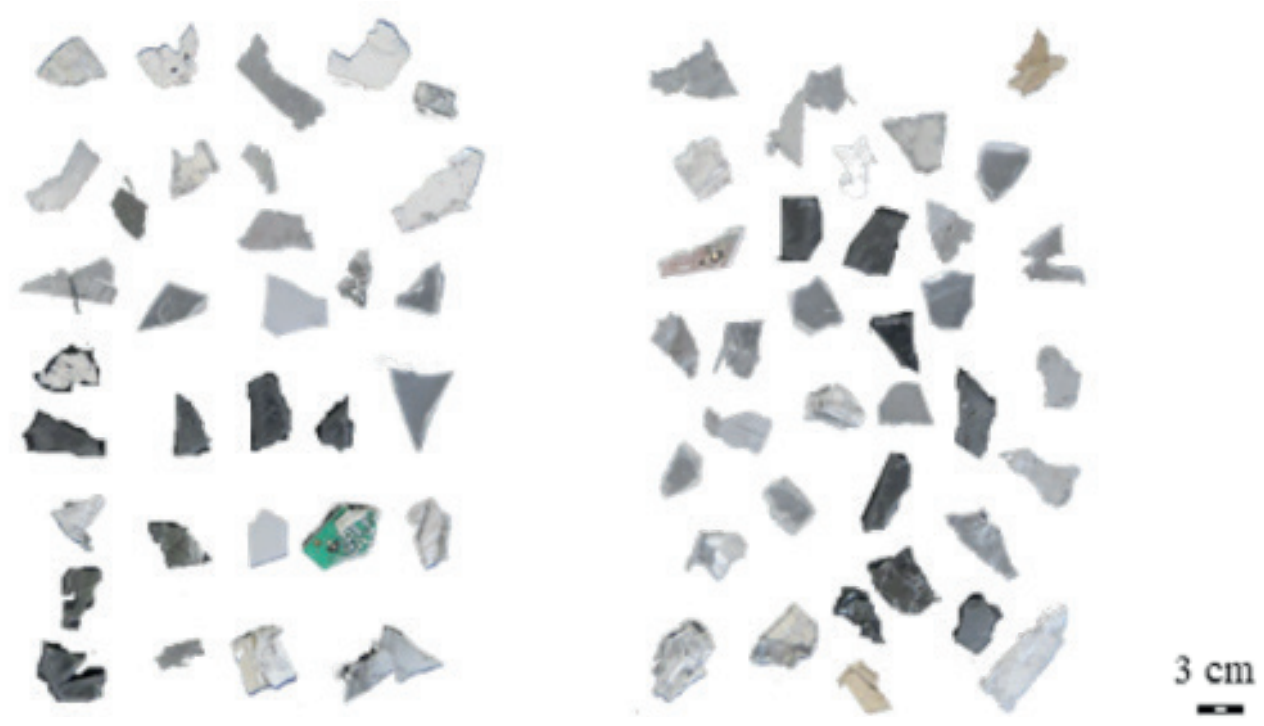

FIGURE 2: Digital images representing the samples used as validation set. 
(Larrechi et al. 2003; Roggo et al. 2007), in clinical application (Gasbarrone et al. 2018; Bonifazi et al. 2018a; Currà et al., 2019) and, more generally, in analytical science (Pasquini, 2003).

In recent years, the use of NIR-HSI has grown rapidly in many sectors, including the solid waste sector (Bonifazi et al., 2019). In literature, different HSI-based approaches are proposed for plastic recycling (Ulrici et al., 2013; Bonifazi et al., 2015), construction and demolition waste recycling (Palmieri et al., 2014; Serranti et al., 2015; Bonifazi et al., 2015; Bonifazi et al., 2017; Bonifazi et al., 2018c) and WEEE recycling (Palmieri et al., 2014; Bonifazi et al. 2018b).

The novelty of the present study relies on the possibility of recognizing different material categories in a specific WEEE stream (i.e. shredded EoL flat monitors and screens) by utilizing a hierarchical modelling-based approach.

\subsubsection{Hyperspectral images acquisitions and data handling}

Hyperspectral imaging acquisitions were carried out at the Raw Materials Laboratory (Latina, Italy) of the Department of Chemical Engineering, Materials and Environment (Sapienza - University of Rome, Italy). A NIR Spectral Camera $^{\mathrm{TM}}$ equipped with an ImSpector ${ }^{\mathrm{TM}}$ N17E (SPECIM Ltd, Finland), a spectrograph working in the Near Infrared wavelength range (i.e.1000 - $1700 \mathrm{~nm}$ ), was used to perform hyperspectral image acquisitions. Spectral Scanner (ver. 1.2) software was used to acquire and collect hyperspectral data. Spectral data were then analyzed using PLS_Toolbox (Version 8.7, Eigenvector Research, Inc.) under MATLAB (Version R2019a, The Mathworks, Inc.) environment.

\subsubsection{Hierarchical classification procedure}

The hierarchical classification procedure was set up based on 3 rules. In other words, three classification steps were performed to recognize different materials constituting the representative sample of the investigated WEEE (Figure 3). In the $1^{\text {st }}$ classification step, LGP fragments (i.e. "Light Guide Panel fragments" class) were distinguished from other materials (i.e. "Other (1)"); in the $2^{\text {nd }}$ step, "Black Plastic" was distinguished from "Other (2)" starting from the "Other (1)" class; in the $3^{\text {rd }}$ classification step, the particles belonging to the "Other (2)" class were identified either as "Metals, PCBs and electrical components" or as "Other (3)". Following this approach, each final recovered product could thus be forwarded to the relevant recycling lines in order to recover metals/alloys and/or plastics.

In order to recognize the different analyzed categories, a Partial Least Squares - Discriminant Analysis (PLS-DA) was applied for each step of the classification, according to a cascade detection procedure (Barker and Rayens, 2003; Ballabio and Consonni, 2013). An ad hoc combination of pre-treatment algorithms was applied to the data for each rule (Rinnan et al., 2009). In the $1^{\text {st }}$ rule, preprocessing algorithms applied were Standard Normal Variate (SNV) and Mean Center (MC); in the $2^{\text {nd }}$ rule, the algorithm applied was $\mathrm{MC}$; in the $3^{\text {rd }}$ rule, preprocessing algorithms applied were SNV, Smoothing and MC. Each model was cross-validated using the Venetian-blinds algorithm.

Since PC and PMMA are the most common polymers in LGP (Chen and Yu, 2007; Hwang and Ko, 2018), an additional classification procedure was set up and implemented to identify polymers. Virgin PC and PMMA were used as training samples in order to recognize the polymer constituting LGP fragments. In this case, PLS-DA was chosen as classification method (Barker and Rayens, 2003; Ballabio and Consonni, 2013) and Mean Center was used as pre-processing algorithm (Rinnan et al., 2009).

\section{EXPERIMENTAL RESULTS}

\subsection{Hierarchical classification}

Raw reflectance spectra used to calibrate the hierarchical classification model is shown in Figure 4. Validation set with real classes and the prediction map, as resulting from the hierarchical classification modelling, are shown in Figure 5. Figure 6 illustrates the reference map of particles. The number of pixels correctly classified (Table 3 ) was computed for each particle, according to its label, as shown in Figure 6.

The hierarchical model reached a Recognition (number of particles correctly assigned divided by the total number of particles in the set) equal to $0.926,5$ particles ( 4 "Oth-

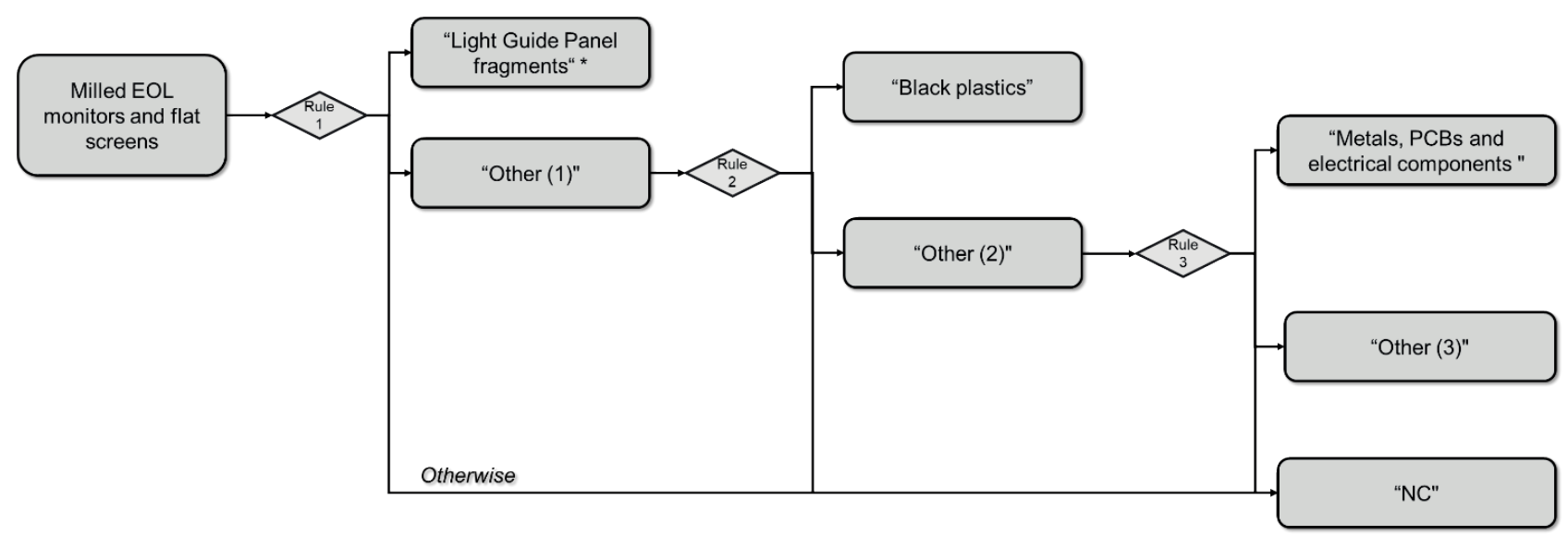

FIGURE 3: Flow-chart of the implemented hierarchical classification modelling. *Starting from Light Guide Panel (LGP) fragments, a classification procedure was applied to perform polymers (PC and PMMA) identification. 


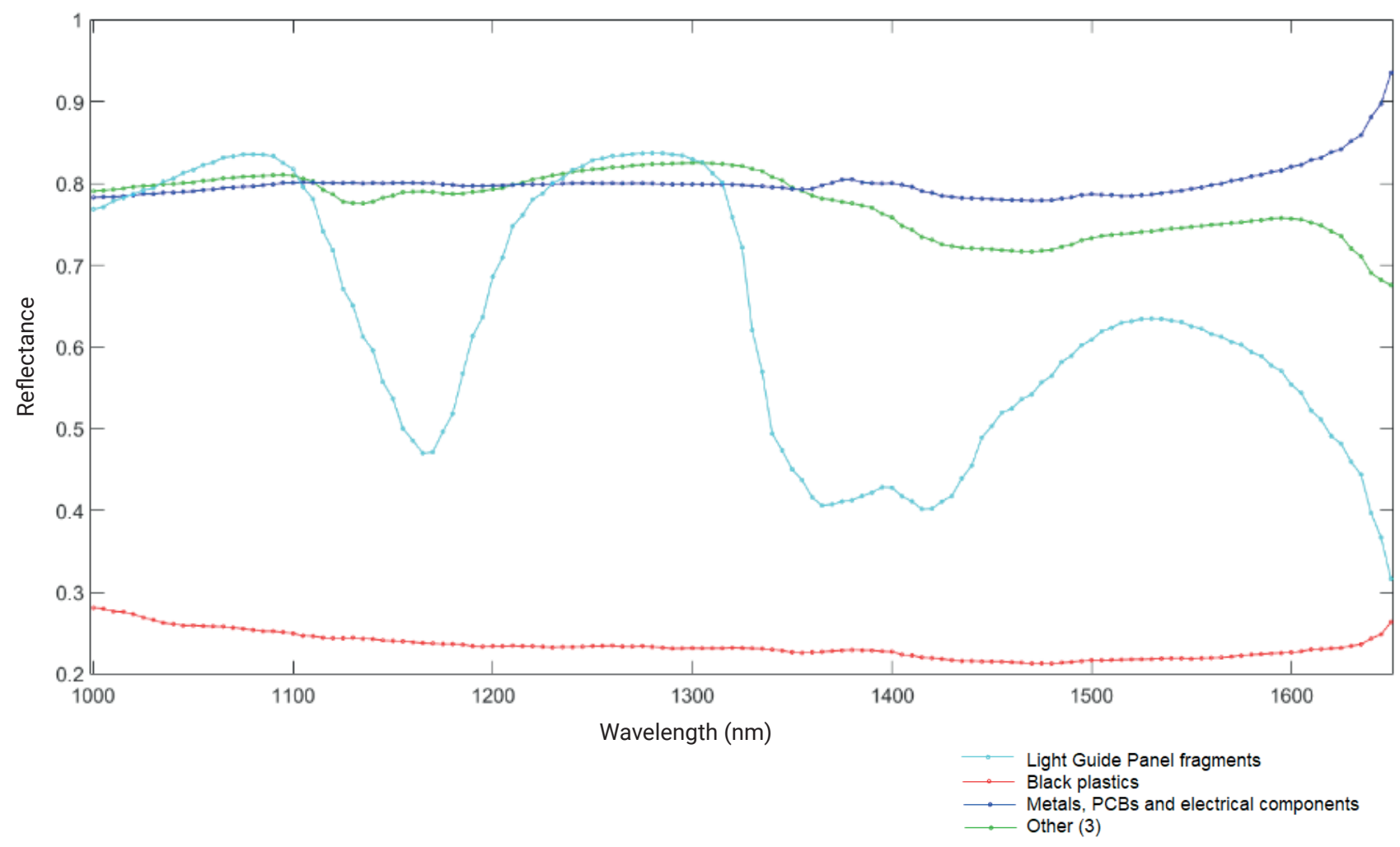

FIGURE 4: Raw spectra of modelled classes from calibration set.

er (3)" particles and 1 "Metals, PCBs and electrical components" particles) out of 68 were not correctly classified (7.35\%).

\subsection{Polymer identification}

The image obtained, including only the particles classified as "LGP fragments", was used as validation set to per- form a new classification addressed at identifying polymer type. Literature reports (Hwang and Ko, 2018) reveal how LGP is mostly constituted by PC or PMMA. This fact can be "simply" verified comparing the reflectance spectra of two polymers: indeed, LGP collected spectral signatures are, on initial visual inspection, very similar to PMMA (Figure 7). To correctly assess LGP polymeric composition, reflectance (a)

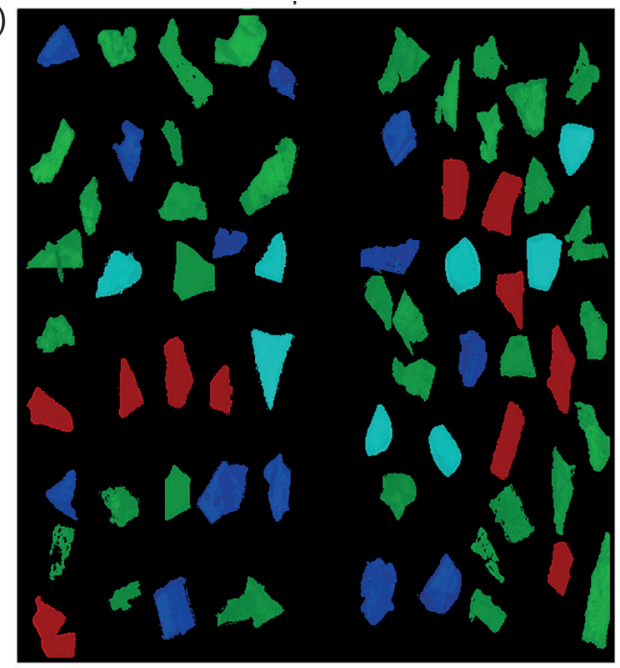

- Light Guide Panel fragments

- Black plastics

- Metals, PCBs and electrical components

- Other (3) (b)

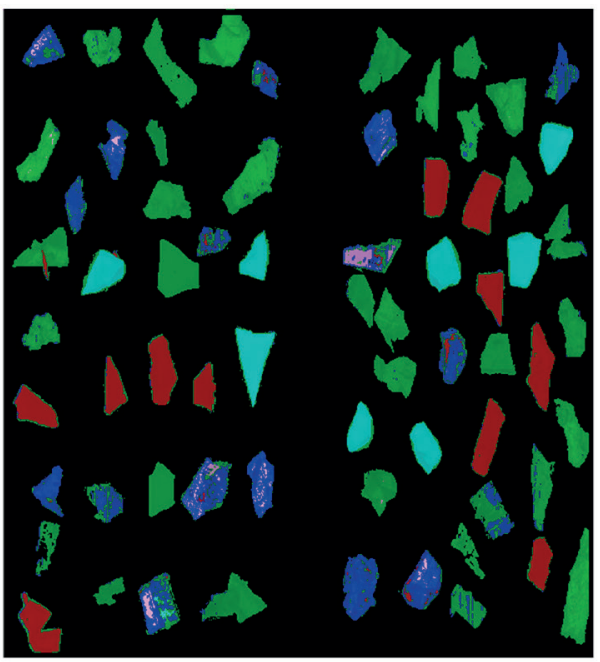

n Light Guide Panel fragments

- Black plastics

- Metals, PCBs and electrical components

- Other (3)

NC

FIGURE 5: Validation set with real classes (a) and the prediction map resulting from the hierarchical classification modelling (b). 


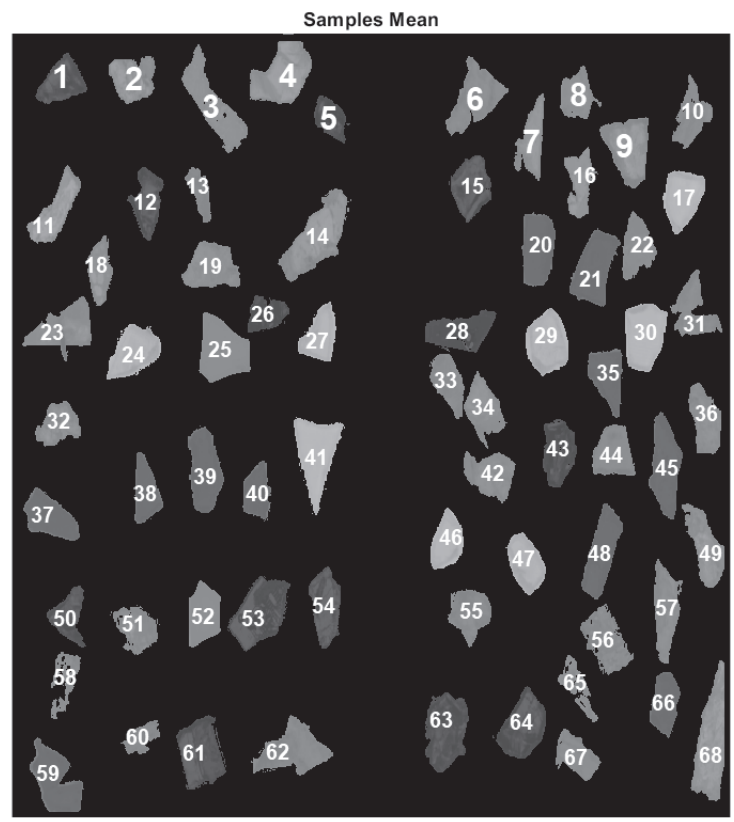

FIGURE 6: Reference map with particle labels used to compute the number of pixels correctly classified for each particle.

spectra of virgin PC and PMMA pellets were acquired and utilized to build the PLS-DA classification model.

Raw reflectance spectra of PC and PMMA classes were pre-processed using the mean center algorithm prior to the classification procedure. Classification results, in terms of prediction map, are shown in Figure 8. Sensitivity and Specificity in calibration, cross-validation and validation are

TABLE 3: Number of pixels correctly classified computed for each particle, reported in Figure 6.

\begin{tabular}{|c|c|c|}
\hline $\begin{array}{l}\text { Particle } \\
\text { label }\end{array}$ & Real Class & $\begin{array}{l}\text { Pixels correctly } \\
\text { classified (\%) }\end{array}$ \\
\hline 1 & Metals, PCBs and Electrical Components & $76.15 \%$ \\
\hline 2 & Other (3) & $95.11 \%$ \\
\hline 3 & Other (3) & $100.00 \%$ \\
\hline 4 & Other (3) & $98.85 \%$ \\
\hline 5 & Metals, PCBs and Electrical Components & $71.50 \%$ \\
\hline 6 & Other (3) & $99.13 \%$ \\
\hline 7 & Other (3) & $100.00 \%$ \\
\hline 8 & Other (3) & $99.51 \%$ \\
\hline 9 & Other (3) & $99.34 \%$ \\
\hline 10 & Other $(3)$ * & $28.60 \%$ \\
\hline 11 & Other (3) & $97.14 \%$ \\
\hline 12 & Metals, PCBs and Electrical Components & $82.33 \%$ \\
\hline 13 & Other (3) & $98.74 \%$ \\
\hline 14 & Other (3) & $97.34 \%$ \\
\hline 15 & Metals, PCBs and Electrical Components & $88.52 \%$ \\
\hline 16 & Other (3) & $95.65 \%$ \\
\hline 17 & Light Guide Panel fragments & $90.33 \%$ \\
\hline 18 & Other (3) * & $19.68 \%$ \\
\hline 19 & Other (3) & $100.00 \%$ \\
\hline 20 & Black plastics & $88.48 \%$ \\
\hline
\end{tabular}

\begin{tabular}{|c|c|c|}
\hline $\begin{array}{l}\text { Particle } \\
\text { label }\end{array}$ & Real Class & $\begin{array}{l}\text { Pixels correctly } \\
\text { classified }(\%)\end{array}$ \\
\hline 21 & Black plastics & $90.12 \%$ \\
\hline 22 & Other (3) & $100.00 \%$ \\
\hline 23 & Other (3) & $95.80 \%$ \\
\hline 24 & Light Guide Panel fragments & $80.87 \%$ \\
\hline 25 & Other (3) & $100.00 \%$ \\
\hline 26 & Metals, PCBs and Electrical Components & $56.97 \%$ \\
\hline 27 & Light Guide Panel fragments & $83.39 \%$ \\
\hline 28 & $\begin{array}{l}\text { Metals, PCBs and Electrical Compo- } \\
\text { nents *** }\end{array}$ & $29.05 \%$ \\
\hline 29 & Light Guide Panel fragments & $84.20 \%$ \\
\hline 30 & Light Guide Panel fragments & $90.14 \%$ \\
\hline 31 & Other (3) & $95.10 \%$ \\
\hline 32 & Other (3) & $92.08 \%$ \\
\hline 33 & Other (3) & $98.89 \%$ \\
\hline 34 & Other (3) & $100.00 \%$ \\
\hline 35 & Black plastics & $84.95 \%$ \\
\hline 36 & Other (3) & $99.15 \%$ \\
\hline 37 & Black plastics & $83.25 \%$ \\
\hline 38 & Black plastics & $81.98 \%$ \\
\hline 39 & Black plastics & $89.53 \%$ \\
\hline 40 & Black plastics & $82.85 \%$ \\
\hline 41 & Light Guide Panel fragments & $86.39 \%$ \\
\hline 42 & Other (3) & $99.64 \%$ \\
\hline 43 & Metals, PCBs and Electrical Components & $69.26 \%$ \\
\hline 44 & Other (3) & $100.00 \%$ \\
\hline 45 & Black plastics & $90.92 \%$ \\
\hline 46 & Light Guide Panel fragments & $83.35 \%$ \\
\hline 47 & Light Guide Panel fragments & $87.50 \%$ \\
\hline 48 & Black plastics & $90.75 \%$ \\
\hline 49 & Other $(3) * *$ & $8.83 \%$ \\
\hline 50 & Metals, PCBs and Electrical Components & $91.93 \%$ \\
\hline 51 & Other (3) * & $43.77 \%$ \\
\hline 52 & Other (3) & $100.00 \%$ \\
\hline 53 & Metals, PCBs and Electrical Components & $71.63 \%$ \\
\hline 54 & Metals, PCBs and Electrical Components & $88.24 \%$ \\
\hline 55 & Other (3) & $99.29 \%$ \\
\hline 56 & Other (3) & $62.42 \%$ \\
\hline 57 & Other (3) & $92.60 \%$ \\
\hline 58 & Other (3) & $92.64 \%$ \\
\hline 59 & Black plastics & $80.74 \%$ \\
\hline 60 & Other (3) & $98.81 \%$ \\
\hline 61 & Metals, PCBs and Electrical Components & $54.37 \%$ \\
\hline 62 & Other (3) & $96.97 \%$ \\
\hline 63 & Metals, PCBs and Electrical Components & $90.82 \%$ \\
\hline 64 & Metals, PCBs and Electrical Components & $81.83 \%$ \\
\hline 65 & Other (3) & $99.72 \%$ \\
\hline 66 & Black plastics & $88.54 \%$ \\
\hline 67 & Black plastics & $85.50 \%$ \\
\hline 68 & Other (3) & $99.96 \%$ \\
\hline
\end{tabular}

* Misclassified as "Metal, PCBs and Electrical components", ** Misclassified as "Black plastics"; *** Not Classified - "NC" 


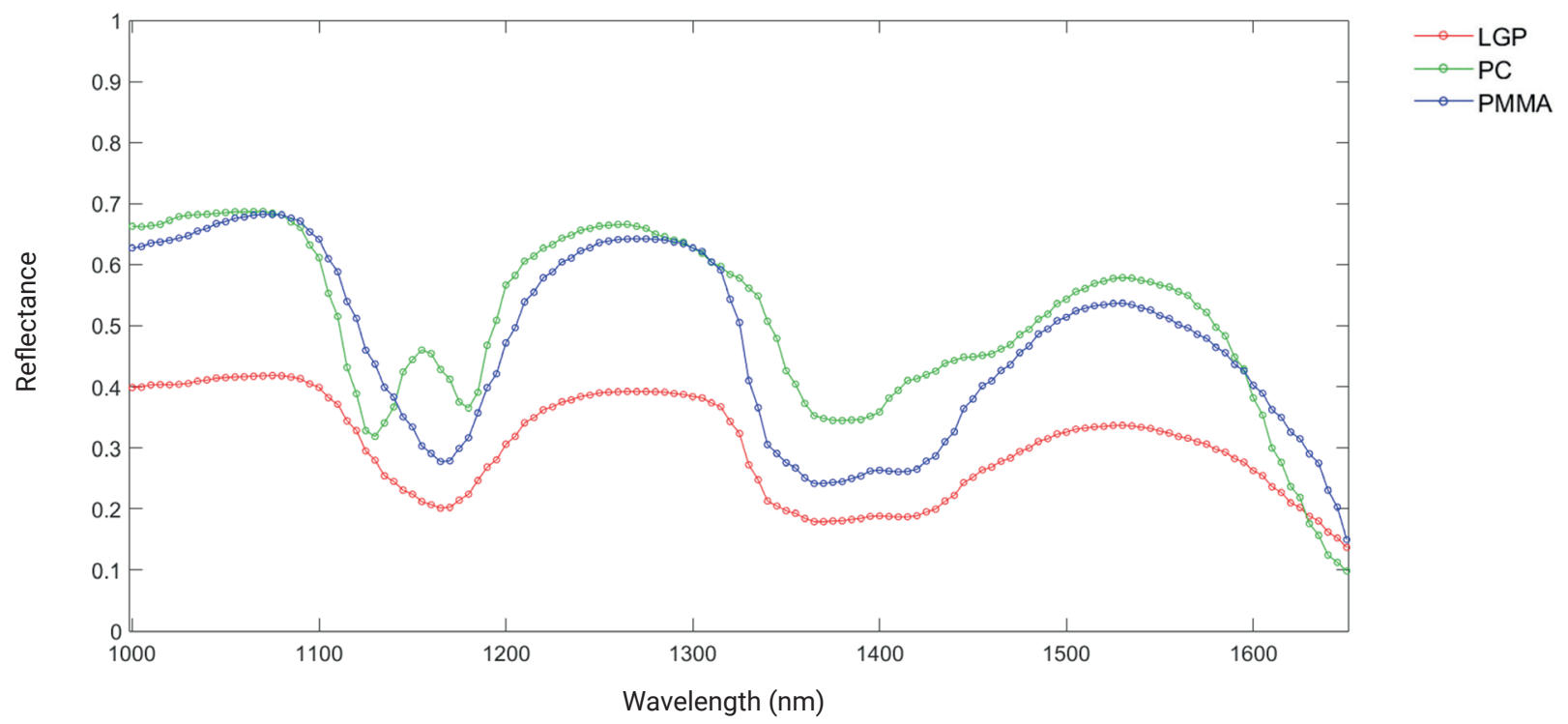

FIGURE 7: Raw spectra of virgin "PC" and "PMMA" polymers compared with LGP spectral signatures.

shown in Table 4: the built model identifies only PMMA as LGP constituent.

\section{CONCLUSIONS}

The present study was carried out with the aim of recognizing different categories of materials present in EoL milled monitors and flat screens using NIR-HSI techniques. Three classifiers were built to identify "Light Guide Panel fragments" (LGP), "Black Plastics" and "Metals, PCBs and electronical components". A hierarchical classification model was set-up and implemented, facilitating identification of the target categories in each step.

Promising results in classification were achieved. The presence of a few misclassified pixels is likely due to light scattering phenomena, sample surface heterogeneity and a possible presence of impurities. In order to improve the classification, a "machine vision" logic capable of assigning only one of the available classes according to a set

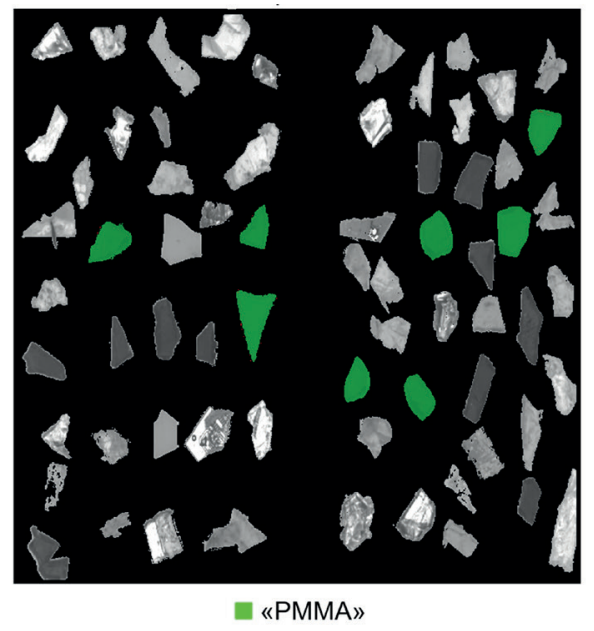

TABLE 4: Performance indicators for PLS-DA model classifying "PC" and "PMMA" polymers.

\begin{tabular}{|c|c|c|c|}
\hline & Class & Sensitivity & Specificity \\
\hline \multirow{2}{*}{ Calibration } & PC & 1.000 & 1.000 \\
\hline & PMMA & 1.000 & 1.000 \\
\hline \multirow{2}{*}{ Cross-validation } & $\mathrm{PC}$ & 1.000 & 1.000 \\
\hline & PMMA & 1.000 & 1.000 \\
\hline \multirow{2}{*}{ Validation } & PC & - & 0.133 \\
\hline & PMMA & 0.866 & - \\
\hline
\end{tabular}

threshold should be implemented. The logic to be used for thresholding should be based on the correctly assigned pixel percentage in each particle domain (e.g. correctly assigned pixels $>50 \%$ of the total pixels included in the particle domain). Therefore, only one class could be attributed to each object in the image to be predicted.

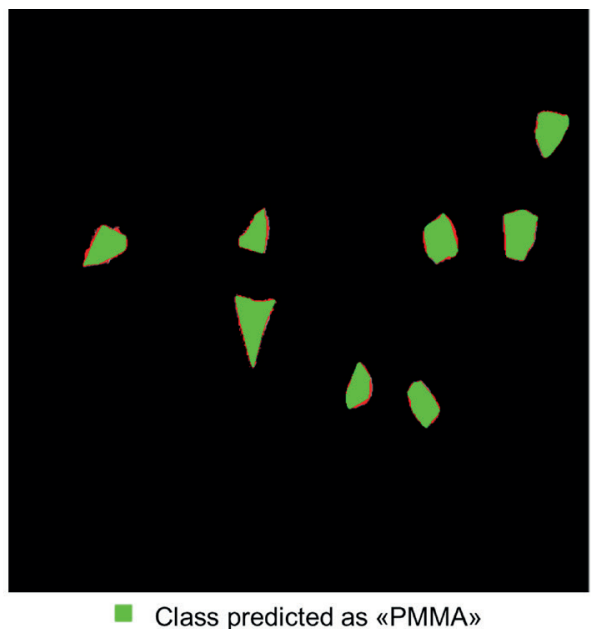

- Class predicted as «PC»

FIGURE 8: Reference map with particle labels used to compute the number of pixels correctly classified for each particle. 
Additionally, HyperSpectral imaging in the NIR range was used to identify Light Guide Panel (LGP) fragments and subsequently recognize the constituting polymer type. An automatic NIR-HSI based recognition system of polycarbonate $(\mathrm{PC})$ and polymethyl methacrylate (PMMA) applied to LGP fragments was developed. More in detail, Partial Least Square Discriminant Analysis (PLS-DA) method was used to set up the classification, starting from virgin pellets used as training set. All LGP fragments were correctly distinguished from the other particles. All LGP fragments were classified as PMMA, which, assuming that only one polymer constituting the analyzed LGP, is a reasonable finding. The results obtained represent a meaningful starting point for the implementation of a fast, non-invasive and reliable procedure for use as a driving force in the separation and quality control of materials originating from spent flat monitor waste stream.

The possibility of conducting a full quality check of materials throughout the entire chain of the recycling plant would likely contribute to the development of "on-line" quality control strategies and facilitate the issuing of material certification directly on site. The proposed approach features the advantages of being rapid, non-destructive and low cost. The reduction of processing costs is an important goal to pursue in the secondary raw materials sector, in which the use of expensive devices should be avoided in order to yield an efficient and economically feasible recycling process. The implemented procedure may be profitably employed to set up on-line strategies aimed at boosting the efficiency of recycling processes, reducing costs and improving the "final quality" of recovered products. Finally, if fully implemented, the proposed NIR-HSI approach would afford the possibility of developing a system capable of recognizing a series of different materials in a WEEE stream, suited to use not only as an analytical core with which to perform quality control, but also as a sorting engine.

\section{REFERENCES}

Agresti, G, Bonifazi, G., Calienno, L., Capobianco, G., Lo Monaco, A., Pelosi, C., Picchio, R. and Serranti, S. 2013. Surface Investigation of Photo-Degraded Wood by Colour Monitoring, Infrared Spectroscopy, and Hyperspectral Imaging. Journal of Spectroscopy.

Ballabio, D. and Consonni, V., 2013. Classification tools in chemistry. Part 1: linear models. PLS-DA. Anal. Methods 5: 3790-3798. 10.1039/C3AY40582F.

Barker, M. and Rayens, W. 2003. Partial least squares for discrimination. Journal of Chemometrics 17: 166-173

Bonifazi, G., Capobianco, G., Palmieri, R. and Serranti, S., 2019, Hyperspectral imaging applied to the waste recycling sector; Spectroscopy Europe, 31(2), pp. 8-11.

Bonifazi, G., Cardillo, A., Currà, A., Gasbarrone, R. and Serranti, S., 2018a. "Near infrared spectroscopy as a tool for in vivo analysis of human muscles ", Proc. SPIE 10662, Smart Biomedical and Physiological Sensor Technology XV, 1066200; doi: 10.1117/12.2304311.

Bonifazi, G., Gasbarrone, R. and Serranti S., 2018b. Characterization of printed circuit boards from e-waste byproducts for copper beneficiation. Proceeding of ECOMONDO 2018, 65-69.

Bonifazi, G., Palmieri, R. and Serranti, S., 2017. Concrete drill core characterization finalized to optimal dismantling and aggregates recovery. Waste Management, 60, pp. 301-310.

Bonifazi, G., Palmieri, R. and Serranti, S., 2015a. Short wave infrared hyperspectral imaging for recovered post-consumer single and mixed polymers characterization. Proceeding Volume 9403, Image Sensors and Imaging Systems 2015; 94030R. https://doi. org/10.1117/12.2081362
Bonifazi, G., Palmieri, R. and Serranti, S., 2015b. Hyperspectral imaging applied to end-of-life (EOL) concrete recycling. Technisches Messen, 82(12), pp. 616-624.

Bonifazi, G., Palmieri, R. and Serranti, S., 2018c, Evaluation of attached mortar on recycled concrete aggregates by hyperspectral imaging. Construction and Building Materials, 169, pp. 835-842

Capobianco, G., Prestileo, F., Serranti, S. and Bonifazi, G., 2015. "Hyperspectral imaging-based approach for the insitu characterization of ancient Roman wall paintings," Periodico di Mineralogia, Special issue (3A), 407-418.

Chancerel, P. and Rotter, S., 2007. Recycling oriented characterisation of WEEE. Proceedings of Eco-X Conference, Vienna, Austria, pp. 205-212.

Chen, G.L. and Yu, T.C., 2007. Surface modification for advanced light guide plate for TFT LCD display (eds. Hinduja S., Fan KC.). Proceedings of the 35th International MATADOR Conference. Springer, London. https://doi.org/10.1007/978-1-84628-988-0_15

Currà, A., Gasbarrone, R., Cardillo, A., Trompetto, C., Fattapposta, F., Pierelli, F., Missori, P., Bonifazi, G. and Serranti, S., 2019. Near infrared spectroscopy as a tool for in vivo analysis of human muscles. Scientific Reports 9, Article number: 8623. https://doi. org/10.1038/s41598-019-44896-8.

Fawcett, T., 2006. An introduction to ROC analysis. Pattern Recogn. Lett. 27 (8): 861-874. https://doi.org/10.1016/j.patrec.2005.10.010.

Gasbarrone, R., Currà, A., Cardillo, A., Bonifazi, G. and Serranti, S., 2018. "Near infrared spectroscopy of human muscles", Proc. SPIE 10489, Optical Biopsy XVI: Toward Real-Time Spectroscopic Imaging and Diagnosis, 1048914; doi: 10.1117/12.2287814.

Geladi, P., Grahn, H. and Burger, J. 2007. Multivariate images, hyperspectral imaging: background and equipment. In: (Grahn, $\mathrm{H}$. and Geladi, P. Eds.) Techniques and Applications of Hyperspectral Image Analysis John Wiley \& Sons, West Sussex, England, pp. 1-15.

Gundapalli, S.P., Hait, S., Thakur, A., 2017. A review on automated sorting of source-separated municipal solid waste for recycling. Waste Manage. 60: 56-74. https://doi.org/10.1016/j.wasman.2016.09.015.

Hwang, I. and Ko, J., 2018. LCD Backlights. In Flat Panel Display Manufacturing (eds. J. Souk, S. Morozumi, F. Luo and I. Bita). doi:10.1002/9781119161387.ch6.

Hyvarinen, T., Herrala, E. and Dall'Ava, A., 1998. Direct signt imaging spectrograph: a unique add-on component brings spectral imaging to industrial applications. In: Proceedings of SPIE Electronic Imaging, 3302, San Jose, California, USA.

Kumaravelu, C., and Gopal, A., 2015. "A Review on the applications of Near-Infrared Spectrometer and Chemometrics for the Agro-Food Processing Industries," Proc. 2015 IEEE International Conference on Technological Innovations in ICT for Agriculture and Rural Development.

Larrechi, M.S., and Callao, M.P., 2003. "Strategy for introducing NIR spectroscopy and multivariate calibration techniques in industry," Trends in Analytical Chemistry, 22, 10.

Lee, W. G., Jeong, J. H., Lee, J. Y., Nahm, K. B., Ko, J. H. and Kim J. H., 2006. Light Output Characteristics of Rounded Prism Films in the Backlight Unit for Liquid Crystal Display. Journal of Information Display, 7(4): 1-4.

Ljungkvist, H., Rydberg, T., Felix, J. and Garmer, K., 2016. Sustainable recycling of flat panel displays: Evaluation of methods for sustainability assessment of LCD waste management scenarios. IVL report C 210. IVL Swedish Environmental Research Institute Ltd. Stockholm, Sweden.

Makenji, K. and Savage, M., 2012. Mechanical methods of recycling plastics from WEEE. In Waste electrical and electronic equipment (WEEE) handbook (eds. V. Goodship and Ab S.), Woodhead Publishing, 212 - 238. https://doi.org/10.1533/9780857096333.2.21 2.

Masoumi, H., Safavi, S. M. and Khani, Z., 2012. "Identification and Classification of Plastic Resins using Near Infrared Reflectance Spectroscopy," International Journal of Mechanical, Aerospace, Industrial, Mechatronic and Manufacturing Engineering, 6(5), 877-884.

Oliveira, C.R.D., Bernardes, A. M. and Gerbase, A.E., 2012. Collection and recycling of electronic scrap: A worldwide overview and comparison with the Brazilian situation. Waste Management 17(8): 1592-1610.

Ongondo, F. O., Williams, I. D. and Cherrett, T. J., 2011. How are WEEE doing? A global review of the management of electrical and electronic wastes. Waste Manage. 31 (4): 714-730. doi: 10.1016/j. wasman.2010.10.023. 
Palmieri, R., Bonifazi, G. and Serranti, S., 2014a. Automatic detection and classification of EOL-concrete and resulting recovered products by hyperspectral imaging. In: Proceedings of SPIE Electronic Imaging, 9106, 91060D, Baltimore, Maryland, USA.

Palmieri, R., Bonifazi, G. and Serranti, S., 2014b. Recycling-oriented characterization of plastic frames and printed circuit boards from mobile phones by electronic and chemical imaging. Waste Manage. 34(11): 2120-2130. https://doi.org/10.1016/j.wasman.2014.06.003

Pasquini, C., 2003. "Near Infrared Spectroscopy: Fundamentals, Practical Aspects and Analytical Applications," J. Braz. Chem. Soc., 14, 2, 198-219.

Rinnan, Å., van den Berg, F. and Engelsen, S. B., 2009. Review of the most common pre-processing techniques for near-infrared spectra. TrAC Trends in Analytical Chemistry 28: 1201-1222. https:// doi.org/10.1016/j.trac.2009.07.007

Robinson B. H. 2009. E-waste: An assessment of global production and environmental impacts. Science of the Total Environment 408(2): 183-191

Roggo, Y., Chalus, P., Maurer, L., Lema-Martinez, C., Edmond, A. and Jent, N., 2007. "A review of near infrared spectroscopy and chemometrics in pharmaceutical technologies," Journal of Pharmaceutical and Biomedical Analysis, 44, 683-700.

Ryan, A., O' Donoghue, L., Lewis, H., 2011. Characterising components of liquid crysal displays to facilitate disassembly. J Clean Prod 19: 1066-1071.

Salhofer, S., Spitzbart, M. and Maurer K., 2011. Recycling of LCD Screens in Europe - State of the Art and Challenges. In: (Hesselbach J., Herrmann C. Eds.). Glocalized Solutions for Sustainability in Manufacturing. Springer, Berlin, Heidelberg, pp.454-458.

Serranti, S., Bonifazi, G. and Gasbarrone, R., 2018a. "Olive fruit ripening evaluation and quality assessment by hyperspectral sensing devices", Proc. SPIE 10665, Sensing for Agriculture and Food Quality and Safety X, 106650R; doi: 10.1117/12.2297352.

Serranti, S., Bonifazi, G. and Gasbarrone, R., 2018b. "Kiwifruits ripening assessment by portable hyperspectral devices", Proc. SPIE 10665 Sensing for Agriculture and Food Quality and Safety X, 106650S; doi: $10.1117 / 12.2297353$.
Serranti, S., Palmieri, R. and Bonifazi, G., 2015. Hyperspectral imaging applied to demolition waste recycling: innovative approach for product quality control. J. Electron. Imag. 24(4) 04003. doi: 10.1117/1.JEl.24.4.043003

Suresh, S. S., Mohanty, S. and Nayak, S. K., 2017. Preparation and characterization of recycled blends using poly(vinyl chloride) and poly(methyl methacrylate) recovered from waste electrical and electronic equipments. Journal of Cleaner Production 149: 863873.

Suresh, S. S., Mohanty, S. and Nayak, S. K., 2018. Preparation of poly(vinyl chloride)/poly(methyl methacrylate) recycled blends: effect of varied concentration of PVC and PMMA in stability of PVC phase on recycled blends. Proceedings of Materials Today 5(2): 88998907.

Tarantili, P.A., Mitsakaki, A.N. and Petoussi, M.A., 2010. Processing and properties of engineering plastics recycled from waste electrical and electronic equipment (WEEE). Polymer Degradation and Stability 95: 405-410.

Teixeira dos Santos, C. A., Lopo, M., N.M.J. Páscoa, R. and A. Lopes, J., 2013. "A Review on the Applications of Portable Near-Infrared Spectrometers in the Agro-Food Industry;" Applied Spectroscopy, $67,11,1215-1233$

Tsuchikawa, S. and Kobori, H., 2015. "A review of recent application of near infrared spectroscopy to wood science and technology," J Wood Sci, 61, 213-220.

Ulrici, A., Serranti, S., Ferrari, C., Cesare, D., Foca, G. and Bonifazi, G. 2013. Efficient chemometric strategies for PET-PLA discrimination in recycling plants using hyperspectral imaging. Chemometr. and Intell. Lab. 122: 31-39. https://doi.org/10.1016/j.chemolab.2013.01.001.

UNEP. 2009. RECYCLING - FROM E - WASTE TO RESOURCES. s.I.: United Nations Environment Programme \& United Nations University.

Veit, H. M. and Bernardes, A. M., 2015. Electronic Waste: Generation and managment. In: (Veit, H. M. and Bernardes, A. M., Eds.) Electronic Waste: recycling techniques. Springer International Publishing Switzerland, pp. 3-10

Zeng, X., Mathewes, J. A. and Li, J., 2018. Urban Mining of E-Waste is Becoming More Cost-Effective Than Virgin Mining. Environmental Science \& Technology 52(8): 4835-4841. 